\title{
Western Consumption Concepts: Cultural Implications, Main Forms and Influences
}

\author{
Weilong Huang ${ }^{1, ~ a}$ and Han Xiao ${ }^{2, b}$ \\ ${ }^{1}$ School of Foreign Languages, Neijiang Normal University, Neijiang 641199, China \\ ${ }^{2}$ Editorial Office of Academic Journal, Xihua University, Chengdu 610039, China \\ ahuberthuang@126.com, b610948374@qq.com
}

Keywords: Western consumption concepts; Forms; Cultural implications; Influences

\begin{abstract}
This paper not only analyzes the cultural implications and main forms of western consumption concepts, but also probes into how western consumption values infiltrate and erode traditional Chinese consumption, and further points out the key to rationally coping with these negative influences, hoping to provide guidance on constructing a scientific and modern consumption view in our country.
\end{abstract}

\section{Introduction}

Consumption concepts, in definition, are views or attitudes that people have on consumption, showing people's affection towards certain goods. They are characterized by human hobbies, cultural trends, historical habits, religious conviction, etc. The attitudes towards consumption are inevitably affected by public views and public behaviors. "Consumption exists not as an economic phenomenon, but as a complex aggregation of economic, psychological, cultural and social factors. Therefore, it seems imperative to study consumption from the perspective of sociology, culture and ecology and other fields." [1]

The western consumptions have in-depth cultural implications. Western countries have evolved their own cultural traditions and customs in their civilization progress and they have different attitudes towards society and life, but they generally have long cherished such values as individualism, hedonism and adventurism in the West. These thoughts deeply influence the forging of their consumption views, and the discussion on the cultural implications of consumption concepts is indispensable from the three values above.

\section{Cultural Implications}

Consumption values definitely reflect cultural connotation. The cultural implications of western consumption can be explored in the following three aspects: individualism, hedonism and adventurism.

Individualism. People from individualism culture are likely to develop independent self-concepts, reflecting their culture in their sense of separateness from others. Those from collectivism culture, on the other hand, are more likely to manifest their self-concept of interdependence. Individualism makes the individual its focus [2] and so starts "with the fundamental premise that the human individual is of primary importance in the struggle for liberation."[3]

It is acknowledged that individualism constitute the core of western culture, while the core function of individualism is obviously embodied in westerners' views on consumption. Most westerners think that they, who create wealth, are entitled to the disposal of wealth in any form of consumption, including distinctive consumption behaviors.

Declaration of Independence, which was drafted by Thomas Jefferson, states that life, liberty and pursuit of happiness are equally endowed to everyone. "We hold these Truths to be self-evident, that all Men are created equal, that they are endowed by their Creator with certain unalienable Rights, 
that among these are Life, Liberty, and the Pursuit of Happiness." [4] Westerners deem individualism as their natural right. Therefore, no matter what consumption they perform, nobody would like to find fault with it. It seems that every consumption style is reasonable and westerners perform consumption simply to satisfy their basic needs.

Hedonism. Hedonism means the pursuit of pleasure, especially the sensual pleasures. Hedonism consumption is another consumption form adopted by westerners for entertainment, be it necessary or not. Nowadays this consumption value is dominant in the western world.

As has been described, westerners regard individualism as the origin of human rights. They respect their own personality and temperament, and they have the liberty to choose whatever consumption forms they like. Therefore, it is individualism that stimulates the formation and development of hedonism.

In fact, most consumption behaviors of westerners can be directly owned to the hedonism. The daily consumptions can serve as a good example of hedonism. Hedonism is prevalent among Americans, who think that their personal rights and freedom are so important that they always choose to safeguard these rights, regardless of other things. In terms of consumption, Americans mostly perform at their will. F. Scott Fitzgerald, one of important novelist of American, successfully depicted the outlook of hedonism spirit in his masterpiece The Great Gatsby. The life styles and consumption values Fitzgerald shaped in The Great Gatsby deeply reflect the pursuit of pleasure by the lost generation, mirroring the Americans of many generations. [5] In the eyes of hedonists, hedonism consumption is one that only focuses on the pursuit of material entertainment, and deems luxurious life as the ultimate aim of their life.

Adventurism. The spirit of tourism adventure occupies an important position in the minds of westerners. Western literature is a good example of adventurism, like Daniel Defoe's Robinson Crusoe and Herman Melville's Moby Dick. Truthfully in the views of westerners, adventurism will stand for a spirit of life, which will promote their success. [6]

The adventurous spirit can be extended in consumption as well. Westerners would like to spend their vacations on tours and they also like to run the risk in investments. They like the newly launched products, regardless of their function and quality. The only thing attracts them is the freshness, for which they dare to run the risk. The history of western countries may help understand the practice of their adventurism. The Puritans, the forefathers of Americans, take the risk of leaving their motherland England for a new land by voyage, hence the birth of New England. American culture consists of two elements: the first one was the motive and expectation which had driven puritans to leave Europe and arrive in a new land; the second one was the environment of America, which is filled with risks. Due to the two elements Americans not only acquire certain political ideas and belief, but also form their own philosophy and values.

The industrial revolution enables the westerners to take the lead in the world. From then on, westerners have begun to control the world and made fortune by invading other countries. During the expansion, the adventurous spirit of westerners was formed at large. Historically the adventurous spirit is valued and pursued by the westerners. And this spirit ultimately was linked with consumption and became a special consumption value.

\section{Main Forms of Western Consumption}

Based on the consumption behaviors of westerners, western consumption can be divided into the following forms: immediate consumption, Deficit Consumption and entertainment consumption.

Immediate Consumption. Immediate consumption means that the consumers immediately exhaust their money rather than doing investment or making deposit. Though immediate consumption meets people's momentary needs for commodities, its negligence in future plan is evident. Today this kind of consumption form is very popular among westerners. Once people have money, most of them would like to buy things, either for spiritual entertainment or for material 
enjoyment. The cut of work time (on average 8 hours per day in American) makes it possible to squeeze much place and time for consumption, and the myriads and various styles of goods will bleed white till the last penny of westerners. And the government provides lots of preferential financial policies to facilitate citizens' consumption.

Entertainment Consumption. Entertainment consumption is another major consumption form for westerners. Westerners indeed know how to enjoy life and spend time. For example, Americans would like to drive their cars whose car-boots are equipped with a powerboat or a small houseboat, taking a journey from Los Angeles to Colorado and enjoying their weekends. This journey of 400-500 miles takes Americans about 4-5 hours, in spite of the racket of California's torrid weather. Besides, they always spend lots of time on drinking, touring and other sorts of entertainments. It is reported that Americans have a large proportion of consumption expenditure in personal item and friends making, entertainment and life, commerce and investment, which is on the increase annually.

Deficit Consumption. Another name for deficit consumption is excessive consumption, which means that people spend the money of tomorrow excessively for the present consumption. For example, when you intend to buy something beyond your financial abilities, then you can pay on credit. The money can be paid by the bank in condition you pay it back to the bank within one month. With lots of convenience, this kind of purchasing style is called deficit consumption.

Nowadays, more and more westerners would like to take the deficit consumption as their primary consumption form. Most of westerners develop the habit of mortgage payment. Different from most Chinese, westerners do not think they should worry too much about the bank loan pressure because they believe that they are able to pay back this money, and they think they should spend every penny in hand to enjoy themselves. Economists explain that they would think conservation as some kind of waste. When lots of money is put into bank, the ability of purchasing power on the whole will be lowered, which will be harmful to the development of economy and society. On the contrary, if they spend the money quickly or borrow some from the bank, it will boost the prosperity of commerce and industry, which will accelerate the circulation of goods and stimulate the demand of high-tech products. Based on the reasons stated above, it can be said that westerners, in order to buy whatever they like, are more likely to exhaust their money or even borrow money from the bank without hesitation.

\section{Influences of Western Consumption Concepts}

Cosmism has been deeply rooted in the westerners as a result of the western consumption values. Cosmism, a very popular social thought in western world after the Second World War, deems the consumption and entertainment higher than any other things. Entertainment consumption, deficit consumption and immediate consumption is a product of the influence of Cosmism. Under the influences of western consumption concepts, the value of Cosmism has gradually been agreed by many Chinese, and the infiltration of western consumption is becoming more and more serious

The Infiltration of Western Consumption Values. With the deepening of reform and opening up, great changes have taken place in China. With the introduction of advanced techniques and equipments, some oversea thoughts, such as western views on consumption, have been blindly applauded by Chinese. In recent years, the western consumption styles can be reflected in the consumption behaviors of Chinese. People today are surely not unfamiliar with the fast food that origins from western country, such as KFC, McDonald and Pizzhut. They have been the indispensable part of Chinese life, but many youngsters have not realized what harm this consumption habit do to their physical health. When we enjoy the convenience and quickness from the fast food, do they really care about the consumption-related health?

What is more, purchasing goods by loan is widely introduced. Like westerners, many Chinese now buy things by loaning money from the bank. The consumption style can be ascribed to the western consumption culture. Chinese have more and more similarities with westerners in the form 
of consumption. They would like to accept the excitement of performing the deficit consumption and entertainment consumption. Especially, the Chinese youth are indulged in newly fashionable suits, cars and other things of foreign brands, which indicate that the traditional Chinese consumption has been infiltrated.

Erosion of Traditional Chinese Consumption Virtues. Western consumption forms have eroded the traditional Chinese consumption virtues of Chinese people, especially the youth. [7][8] In China, western consumption forms directly affect Chinese people's life goals and attitudes. The youth, especially the students, weight the burden of their parents through the luxurious consumption, competitive consumption and other strange consumption styles, which are harmful to the harmony between the students and their parents.

Traditional moral virtues benefit the harmonious development of human, society and nature. It is known that frugal and thrifty spirit has long been the traditional Chinese moralities in consumption, which became our spiritual power to help our nation overcome all kinds of difficulties, so that it could stand out among many other nations in the world. However, with the popularity of Cosmism and the infiltration of western consumption values, traditional Chinese views and attitudes towards consumption have been eroded. Besides, it also impeded the progress of the cultivation of frugality and diligence of Chinese.

Countermeasures. In the context of negative influence of western consumption values on Chinese, there are several ways to cope with the erosion of traditional Chinese consumption view. First of all, it is necessary to integrate social education, school education and family education in terms of the advocacy of scientific and healthy consumption habits, that is, establish and advocate scientific views on consumption to resist the negative influence of western views. [9] The essence and danger of western consumption forms in theory should be publicized in society, school and family. Then, the youngsters themselves should further cultivate the modern views on consumption to adjust to the environment of our country and really embody the truthful meaning of consumption. [10] In information society, the mass media can play the role of publicizing rational consumption concept, to resist the invasion of western views on consumption.

\section{Summary}

From what is stated above, we have come to the conclusion that when we introduce western views and styles of consumption, we should also be alert of the negative influence, for they may do harm to the youth as well as to the social and economic development of our country. Furthermore, consumption embodies more in the historical tradition and cultural connotation. Therefore, we must advocate the scientific and modern views on consumption from the perspective of traditional Chinese consumption virtues.

\section{References}

[1] N. Wang: Sociology of Consumption: An Perspective of Analysis (Social Sciences Academic Press, China 1998), p.11.

[2] Information on http://www.britannica.com/EBchecked/topic/286303/individualism.

[3] L.S. Brown: The Politics of Individualism: Liberalism, Liberal Feminism, and Anarchism (Black Rose Books Ltd., Canada 1993).

[4] Information on http://www.ushistory.org/Declaration/document/.

[5] W. Tang: Dongjiang Journal, (2014) No. 1, pp. 45-50.

[6] C.Y. Zhang: A Comparative Study of Western and Chinese Culture (Hunan People's Publishing House, China 2004). 
[7] Y.L. Ling: Journal of Socialist Theory Guide, (2013) No.2, pp.19-21.

[8] H.Y. Liu, X. Liu: Contemporary Educational Science, (2010) No. 19, pp. 47-50.

[9] H. Zhang, Z. B. Duan, L. Zhou, J. Q. Li: Education Exploration, (2007) No. 06, pp. 129-130.

[10] J. H, M. Q. Zhang: Journal of Guizhou Normal University (Social Sciences), (2005) No.4, pp. 6-11. 